\title{
In vitro effect of polyethylene glycol and sorbitol on two banana varieties viz. Grand naine and Nalla bontha to study drought stress
}

\author{
Ashu Singh \\ Department of Agricultural Biotechnology, College of Agriculture, Sardar Vallabhbhai Patel \\ University of Agriculture and Technology, Meerut-250110 (U.P.), India \\ Pradeep Kumar Shukla \\ Department of Biological Sciences, Faculty of Basic Sciences, Sam Higginbottom University \\ of Agriculture, Technology and Sciences, Prayagraj-211007 (U.P.), India

\section{R. S. Sengar} \\ Department of Agricultural Biotechnology, College of Agriculture, Sardar Vallabhbhai Patel \\ University of Agriculture and Technology, Meerut-250110 (U.P.), India \\ Pragati Mishra* \\ Department of Molecular and Cellular Engineering, Jacob Institute of Biotechnology and \\ Bioengineering, Sam Higginbottom University of Agriculture, Technology and Sciences, \\ Prayagraj-211007 (U.P.), India \\ *Corresponding author. Email: pragati.misra@shiats.edu.in
}

\section{How to Cite}

Singh, A. et al. (2021). In vitro effect of polyethylene glycol and sorbitol on two banana varieties viz. Grand naine and Nalla bontha to study drought stress. Journal of Applied and Natural Science, 13(2), 482 - 490. https://doi.org/10.31018/jans.v13i2.2579

\begin{abstract}
Water stress is one of the foremost categories of stress damaging plants' overall growth and development. The aim of the present study was to explore and demonstrate stress-induced drought to calibrate changes in stress parameters of two banana plant varieties viz. Grand naine (G9) and Nalla bontha were cultured in Murashige and Skoog medium (MS) media supplemented with stress inducers -Poly ethylene glycol (PEG) and sorbitol. The different concentrations of inducers were used to induce drought stress in two varieties of banana with contrasting characters for drought condition. The study indicated that PEG contrived mild to moderate osmotic stress and so does the alditol i.e. sorbitol on in vitro banana plants. The different concentrations of PEG and sorbitol produced significant effects on various parameters. The maximum decrease in shoot length was prominent in G9(52\%) as compared to Nalla bontha (11\%). When treated with $3 \%$ w/v sorbitol, even average root length showed the same level of damage with G9(59\%) while in case of Nalla bontha there was a $17 \%$ decrease. The banana plantlet produced in vitro was estimated at one and two weeks after inoculation, respectively. Proline content tended to increase as the concentration of osmotic inducers increased (-44\% in G9 at $3 \%$ w/v sorbitol), whereas RWC (8.9\% in G9 at $3 \% \mathrm{w} / \mathrm{v} \mathrm{Peg})$ showed an opposite effect. It was concluded that quantitative and qualitative changes in physiological (shoot and root length) and biochemical (Proline and relative water content, RWC) parameters played an important role in plants under drought stress conditions. This pattern varied from species to species. This work has been attempted for the first time in banana, especially Grand naine varieties with contrasting characters under induced drought stress.
\end{abstract}

Keywords: Banana, Drought tolerance, Oxidative damage, RWC, Proline, Stress, Sorbitol

\section{INTRODUCTION}

As a natural climatic feature with a varying degree of intensity, drought occurs in almost all climatic zones. While differing in strength and duration, drought is among the most dangerous ecological stresses. (Wilhite and Donald 1993; Zhang, 2007). Indeed, even a temporary water deficit results in substantial yearly crop yield losses (Shao et al., 2009; Basu et al., 2016), which hinder sustainable agriculture worldwide (Farooq et al., 2009; Jaleel et al., 2009; Anjum et al., 2015). Hence, due to future climatic predictions in terms of the frequency and length of drought cycles, it may be the most significant challenges of the current century (Trenberth et al., 2014; Zhao et al., 2015). Drought avoidance, drought prevention, and drought tolerance 
are the three main strategies used by a plant to survive this physiologically unbearable situation under water scarcity (Zhang et al., 2014).

Bananas and plantains are a chief staple food and export commodity in many countries with global average banana production rising from 69 million tons in 20002002 to 116 million tons in 2017-2019, with an estimated USD 31 billion. Banana is being produced about 32 million metric tons across India. (Food and Agriculture Organization , 2019). Though India ranks first in banana production, it contributes about 24 per cent ( 26.5 million metric tons) to the world's total banana pool and covers approximately $7,76,000$ hectares of agricultural land. The average national productivity is $34.2 \mathrm{MT} / \mathrm{Ha}$. Banana also has the highest production of all fruit in India (33\%) (Bikram and Bandita 2019). India is a major exporter of fruit and exported 50,000 MT bananas worth INR 13,064 lakh during 2011-2012, with the major export destinations being the UAE, Saudi Arabia, Iran, Kuwait and Bahrain. Banana contributes $37 \%$ of the total fruit production in India. It helps the livelihoods of millions of people. (Bisht et al., 2015)

Drought stress is a consequence of prolonging water scarcity, which adversely affects plant growth. Thus, drought stress is addressed worldwide due to its severity, while we know that many genes confer drought tolerance, which is really a qualitative trait and thus, the regulation of these ecologically expressed traits is a mammoth challenge (Ravi et al., 2013). Despite these limitations, the pool of banana genes is very rich and provides a great opportunity to exploit the quantitative and complex characteristics, including drought tolerance. In vitro estimation of drought tolerance has been studied in Triticum species (Khan et al., 2019), maize (Matheka et al., 2008), cane sugar (Yadav et al., 2006) and Tagetes (Mohamed et al., 2000). These investigators used non-penetrative osmotic stress-inducing agents incorporated in the media. Ober and Sharp (2003) using refined mannitol and polyethylene glycol (PEG) concluded that it had no deleterious or toxic effect on the banana plant, but had an impact on growth by lowering the medium's water potential in the sense that the plant could not absorb the water required for growth. Recent climate change concerns have justified the need to cultivate commercial varieties of bananas suitable to less water-based environments. Growth retardation is a prime parameter to calibrate the level of tolerance a plant has under drought stress because growth is directly linked to mass. The fundamental parameter of growth reduction is biomass loss, which is a method to define a tolerant variety among genotypes (Sharma et al., 2019). Bananas, which are commercial crops in the tropical and subtropical regions of the world, are vulnerable to their growth and productivity being adversely affected by water stress. The objective of the present study was to analyze the effects of stress inducers viz.
PEG and Sorbitol to develop an in vitro technique to screen for drought-tolerant banana varieties by demonstrating their growth parameters.

\section{MATERIALS AND METHODS}

\section{Methodology \\ Culture media}

Murashige and Skoogs. 1962 (MS) media supplemented with plant growth regulators, $3 \%$ sucrose solidified with $0.7 \%$ agar was used throughout the study. The $\mathrm{pH}$ of the medium was adjusted to 5.8 prior to autoclave at 15 psi pressure, $121^{\circ} \mathrm{C}$ for $15-20 \mathrm{~min}$. The medium was finally allowed to cool and solidify. They were kept under aseptic conditions at least for 2-3 days before inoculation.

\section{Sterilization of explant}

The plant material (sword suckers) of two banana cultivars (Grand naine and Nalla bontha) used in the present research work was collected from the banana fields established at field laboratory and experiment station, Department of Agricultural Biotechnology, Sardar Vallabhbhai Patel University of Agriculture \& Technology (SVPUA\&T) Meerut. The plant materials of banana were washed thoroughly for $30 \mathrm{~min}$. under running tap water by using a beaker covered with gauge to remove microbial load and dust particles. Then explants were washed 4-5 times with distilled water to make material free from tween 20 then they were treated with $0.1 \%$ bavestin and $0.1 \%$ indofil for $15-20$ minutes and then were washed with distilled water 3-5 times, outer leaves were peeled off.

\section{Establishment and proliferation of banana explants in in vitro culture}

The surface sterilized explants with a meristem were directly inoculated to the jam bottles containing $20 \mathrm{ml}$ of MS medium supplemented with different concentration of auxins (IAA) and cytokinins (BAP). The growth room and allowed to grow in controlled environment. The temperature of the growth room was maintained within $25 \pm 1^{\circ} \mathrm{C}$ by an air conditioner. A 16/8-hour light/ dark cycle was maintained with the light intensity of 1000 lux for the growth and development of culture.

\section{Stress induction}

Sorbitol is a solute that is normally not metabolized by plants, and PEG is an impermeable, long-chain polymer. These compounds induce water stress by both reducing the osmotic potential of the culture medium and not being metabolized by the plants. Different osmotic stress inducers such as PEG and sorbitol were added directly into the MS medium to induce stress condition. MS medium was supplemented with a different osmotic inducer $(0 \%, 1 \%, 2 \%$ and $3 \%$ PEG and 0 
$\mathrm{mM}, 0.02 \mathrm{mM}, 0.04 \mathrm{mM}$ and $0.06 \mathrm{mM}$ sorbitol) to investigate the effect of drought stress on in vitro shoot multiplication and rooting in banana genotypes. The different preparations of MS medium complemented with variable concentrations of the inducers were tested on these two most grown banana varieties. The experiment was planned with three to five replicates per drought treatment and it was repeated three times. The physio-biochemical parameters viz. phenotypic characters (Root and Shoot lengths) were calculated after one week of inoculation and the proline content was estimated at two weeks after inoculation by the method of Bates et al., (1973) and RWC was also calculated at two weeks after inoculation using method suggested by Barrs and Wheatherly (1962) of two distinct banana genotypes.

\section{Statistical analysis of data on in vitro experiments} All the experiments were conducted in a complete randomized design (CRD) with a minimum of three replicates $(n=3)$ per treatment and repeated thrice. One replicate means one culture vessel. For statistical analysis of data generated through in vitro experiments, the effect of different treatments on various parameters was quantified. The significance of difference among means was determined by analysis of variance (ANOVA) by using SPSS statistics version 19.02 software [SPSS, Chicago, USA]. The values are mean SE for three samples in each group, $P$ values $\leq 0.05$ were considered as significant.

\section{RESULTS AND DISCUSSION}

\section{Effect of osmotic stress inducers on the growth of banana varieties}

In-vitro shoot multiplication and rooting experiments carried out on basal MS media and 1/2-MS media respectively in combination with different concentrations of PEG i.e.; $0 \%, 1 \%, 2 \%$ and $3 \%(\mathrm{w} / \mathrm{v})$ showed significant differences among the various plant growth parameters such as number of shoots per explants, shoot length, number of roots per shoots and root length of Grand Naine and Nalla Bontha genotypes of banana (Table 1 and Fig. 1).

As it is evident from the data represented, the maximum number of shoots per explants $(8.1 \pm 1.15)$ was recorded in MS media without PEG and minimum in $3 \%(w / v)$ PEG (3.4 \pm 0.56$)$. It can be inferred from the table that with the increase in PEG concentration, the rate of formation of shoots decreased. Similarly, the highest shoot length $(3.3 \pm 0.24)$ was recorded in medium without PEG and the lowest in 3\% (w/v) PEG (2.8 $0.04)$ with minimum number of shoots $(5.1 \pm 0.56)$. Likewise, the longest shoot length $(3.7 \pm 0.14)$ was recorded on medium without PEG supplementation and the shortest shoot length $(2.9 \pm 0.04)$ was recorded in $3 \%$ (w/v) PEG concentration. It can be inferred from the data presented in Table 1 that as the concentration of PEG increased to $3 \%(\mathrm{w} / \mathrm{v})$, the average number of shoots per explant and shoot length decreased.

Similarly, significant differences were observed in shoot growth of Nalla Bontha explants on different PEG concentrations maximum number of shoots were recorded on medium without PEG concentration $(7.9 \pm 1.00)$ i.e. control medium, minimum number of shoots $(5.1 \pm 0.56)$ were observed on $3 \%(\mathrm{w} / \mathrm{v}) \mathrm{PEG}$. Likewise, the longest

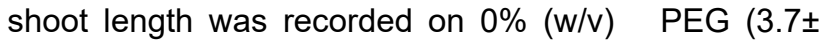
$0.14)$ and shortest shoot length $(2.9 \pm 0.04)$ were seen in $3 \%(\mathrm{w} / \mathrm{v})$ of PEG concentration. It can be inferred from the data presented in Table 1 that as the concentration of PEG increases, the average number of shoots per explant and shoot length decreases. While the formation of roots and root length in Nalla Bontha genotype on culture media with different concentrations of PEG followed the same pattern. As the PEG concentration increased, the rate of root formation and roots length decreased. All the values recorded were statistically significantly different from each other. It is apparent from Table 1 that maximum number of roots were observed in 1/2- MS media without PEG supplemented $(18.9 \pm 1.54)$ and the minimum number of roots formation (14.4 \pm 1.14$)$ were observed on $3 \%(\mathrm{w} / \mathrm{v})$ PEG medium. Likewise, the highest root length $(8.4 \pm 0.14)$ was observed in control without any PEG concentration and the lowest root length $(7.6 \pm 0.14)$ were recorded in $3 \%(\mathrm{w} / \mathrm{v})$ PEG. Likewise, the root formation and root length also followed similar relation. With an increase in PEG concentration, roots formed and length of roots decreases, the maximum number of roots per shoot $(17.1 \pm 1.14)$ were observed in medium without PEG and the minimum at $3 \%(w / v)$ PEG $(7.4 \pm 1.16)$, whereas the highest $8.4 \pm 0.14$ and the lowest root length $7.6 \pm$ 0.14 were recorded at control PEG concentration and $3 \%(w / v)$ PEG respectively.

As it is evident from the data of Table 2 for Grand Naine, the maximum number of shoots per explants $(11.0 \pm 1.00)$ were in control i.e. $0.0 \mathrm{mM}$ sorbitol concentration and the minimum number of shoots per explants $(3.4 \pm 0.56)$ in $0.06 \mathrm{mM}$ concentration of sorbitol. It was inferred from the table that with the increase in sorbitol concentration, the rate of formation of shoots

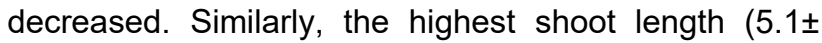
0.15 ) was recorded at $0.0 \mathrm{mM}$ sorbitol and the lowest shoot length $(2.4 \pm 0.15)$ in $0.06 \mathrm{mM}$. Likewise, the root formation and root length also followed a similar pattern. With an increase in sorbitol concentration, roots formed and length of roots decreased The maximum number of roots per shoot $(15.0 \pm 1.43)$ were observed at $0.0 \mathrm{mM}$ sorbitol concentration and minimum number of roots per shoot $(3.2 \pm 0.59)$ at $0.06 \mathrm{mM}$, whereas highest root length $10.0 \pm 0.14$ and the lowest root length $4.1 \pm 0.20$ were recorded at $0.0 \mathrm{mM}$ and $0.06 \mathrm{mM}$ 
Singh, A. et al. / J. Appl. \& Nat. Sci. 13(2), 482 - 490 (2021)

Table 1. Effect of various PEG concentrations on plant growth of banana genotypes.

\begin{tabular}{|c|c|c|c|c|}
\hline Parameters evaluated & 0 PEG \%(w/v) (Control) & $1 \%(w / v)$ PEG & $2 \%(w / v)$ PEG & $3 \%(w / v)$ PEG \\
\hline \multicolumn{5}{|c|}{ Grand Naine } \\
\hline Average no. of shoots/explants & $8.1 \pm 1.15^{a}$ & $5.9 \pm 0.58^{a b}$ & $4.5 \pm 1.53^{b c}$ & $3.4 \pm 0.56^{c}$ \\
\hline Average shoot length & $3.3 \pm 0.24^{\mathrm{ab}}$ & $2.9 \pm 0.16^{\mathrm{ab}}$ & $3.0 \pm 0.26$ & $2.8 \pm 0.04^{c}$ \\
\hline Average no. of roots/explant & $17.1 \pm 1.14^{\mathrm{a}}$ & $13.2 \pm 1.00^{b}$ & $9.1 \pm 1.00^{c}$ & $7.4 \pm 1.16^{c}$ \\
\hline Average root length & $8.2 \pm 0.54^{a}$ & $5.0 \pm 0.14^{b}$ & $4.5 \pm 0.04^{b c}$ & $4.3 \pm 0.20^{c}$ \\
\hline \multicolumn{5}{|c|}{ Nalla Bontha } \\
\hline Average no. of shoots/explants & $7.9 \pm 1.00^{a}$ & $6.9 \pm 1.00^{a}$ & $6.2 \pm 0.56^{a b}$ & $5.1 \pm 0.56^{b}$ \\
\hline Average shoot length & $3.7 \pm 0.14^{\mathrm{a}}$ & $3.3 \pm 0.14^{\mathrm{ab}}$ & $3.2 \pm 0.12^{b c}$ & $2.9 \pm 0.04^{c}$ \\
\hline Average no. of roots/explant & $18.9 \pm 1.54^{\mathrm{a}}$ & $18.2 \pm 0.57^{\mathrm{ab}}$ & $16.7 \pm 0.14^{b}$ & $14.4 \pm 1.14^{\mathrm{c}}$ \\
\hline Average root length & $8.4 \pm 0.14^{a}$ & $8.3 \pm 0.10^{a}$ & $8.2 \pm 0.14^{a}$ & $7.6 \pm 0.14^{b}$ \\
\hline
\end{tabular}

Data represents mean \pm SE of three replicates per treatment in three repeated experiments. Means within the same column followed by the different letters are significantly different according to DMRT at $5 \%$ level.

Table 2. Effect of various Sorbitol concentrations on plant growth of banana genotype Grand naine and Nalla Bontha.

\begin{tabular}{|c|c|c|c|c|}
\hline Parameters evaluated & 0.0mM Sorbitol (Control) & $0.02 \mathrm{mM}$ Sorbitol & $0.04 \mathrm{mM}$ Sorbitol & $0.06 \mathrm{mM}$ Sorbitol \\
\hline \multicolumn{5}{|c|}{ Grand Naine } \\
\hline $\begin{array}{l}\text { Average no. of shoots/ } \\
\text { explants }\end{array}$ & $11.0 \pm 1.00^{a}$ & $7.4 \pm 1.14^{b}$ & $5.1 \pm 1.00^{c}$ & $3.4 \pm 0.56^{c}$ \\
\hline Average shoot length & $5.1 \pm 0.15^{a}$ & $4.3 \pm 0.12^{b}$ & $4.0 \pm 0.10^{c}$ & $2.4 \pm 0.15^{d}$ \\
\hline $\begin{array}{l}\text { Average no. of roots/ } \\
\text { explant }\end{array}$ & $15.0 \pm 1.43^{a}$ & $11.0 \pm 1.43^{b}$ & $4.7 \pm 1.43^{c}$ & $3.2 \pm 0.59^{c}$ \\
\hline Average root length & $10.0 \pm 0.14^{\mathrm{a}}$ & $9.1 \pm 0.14^{b}$ & $5.2 \pm 0.10^{\mathrm{c}}$ & $4.1 \pm 0.20^{d}$ \\
\hline \multicolumn{5}{|c|}{ Nalla Bontha } \\
\hline $\begin{array}{l}\text { Average no. of shoots/ } \\
\text { explants }\end{array}$ & $11.3 \pm 0.55$ & $9.5 \pm 0.56$ & $8.1 \pm 1.51$ & $7.9 \pm 1.00$ \\
\hline Average shoot length & $4.5 \pm 0.14^{\mathrm{a}}$ & $4.0 \pm 0.11^{b}$ & $4.2 \pm 0.20^{b c}$ & $4.0 \pm 0.15^{c}$ \\
\hline $\begin{array}{l}\text { Average no. of roots/ } \\
\text { explant }\end{array}$ & $10.9 \pm 1.00^{a}$ & $9.7 \pm 0.57^{\mathrm{ab}}$ & $8.7 \pm 0.57^{b c}$ & $7.4 \pm 1.14^{c}$ \\
\hline Average root length & $8.5 \pm 0.25^{a}$ & $7.4 \pm 0.14^{b}$ & $7.6 \pm 0.10^{b}$ & $7.0 \pm 0.14^{c}$ \\
\hline
\end{tabular}

Data represents mean \pm SE of three replicates per treatment in three repeated experiments. Means within the same column followed by the different letters are significantly different according to DMRT at $5 \%$ level.

sorbitol respectively.

Same pattern was done for Nalla Bontha banana genotype. The data presented in Table 2 showed the effect of osmotic inducer sorbitol on morphogenetic responses (shooting and rooting) of Nalla Bontha explants. Significant differences were observed on shoot growth of Nalla Bontha explants exposed to different concen-

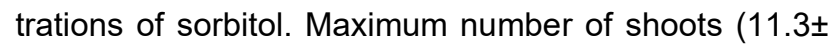
0.55 ) were recorded on $0.0 \mathrm{mM}$ sorbitol concentration or control medium and the minimum number of shoots $(7.90 \pm 1.00)$ were observed on $0.06 \mathrm{mM}$. Likewise, the longest shoot length $(4.5 \pm 0.14)$ was recorded on 0.0 $\mathrm{mM}$ and the shortest shoot length $(4.0 \pm 0.15)$ were seen in $0.06 \mathrm{mM}$ of sorbitol concentration. It was inferred from the data presented in Table 2 that as the Sorbitol concentration increased from $0.0 \mathrm{mM}$ to 0.06 $\mathrm{mM}$, the average number of shoots per explant and shoot length decreased. Gopal and Iwama (2007) observed a severe reduction in potato plantlets' foliage growth on a culture media with 0.3 and $0.4 \mathrm{M}$ sorbitol.
Sorbitol at high concentrations may induce a very strong osmotic stress that exceeds the osmotic adjustment plantlet capacity. Consequently, plantlets grown on these culture media suffered from a severe water deficit due to high osmotic stress. These could be the causes of reduced plantlet growth observed in the stressing medium through this study. The same reduction in plantlets growth (Shoot, root number and shoot, root length) was observed in the present study.

Similarly, the formation of roots and root length in Nalla Bontha genotype on different sorbitol concentrations followed the same relation. As the sorbitol concentration increased, the rate of root formation and roots length decreased.

All the values recorded are statistically significant different among each other. It is apparent from Table 2 that the maximum number of roots $(10.9 \pm 1.00)$ were observed in $1 / 2$ - MS media supplemented with $0.0 \mathrm{mM}$ sorbitol concentration and the minimum number of roots formation $(7.4 \pm 1.14)$ were observed on $0.06 \mathrm{mM}$ sorbi- 


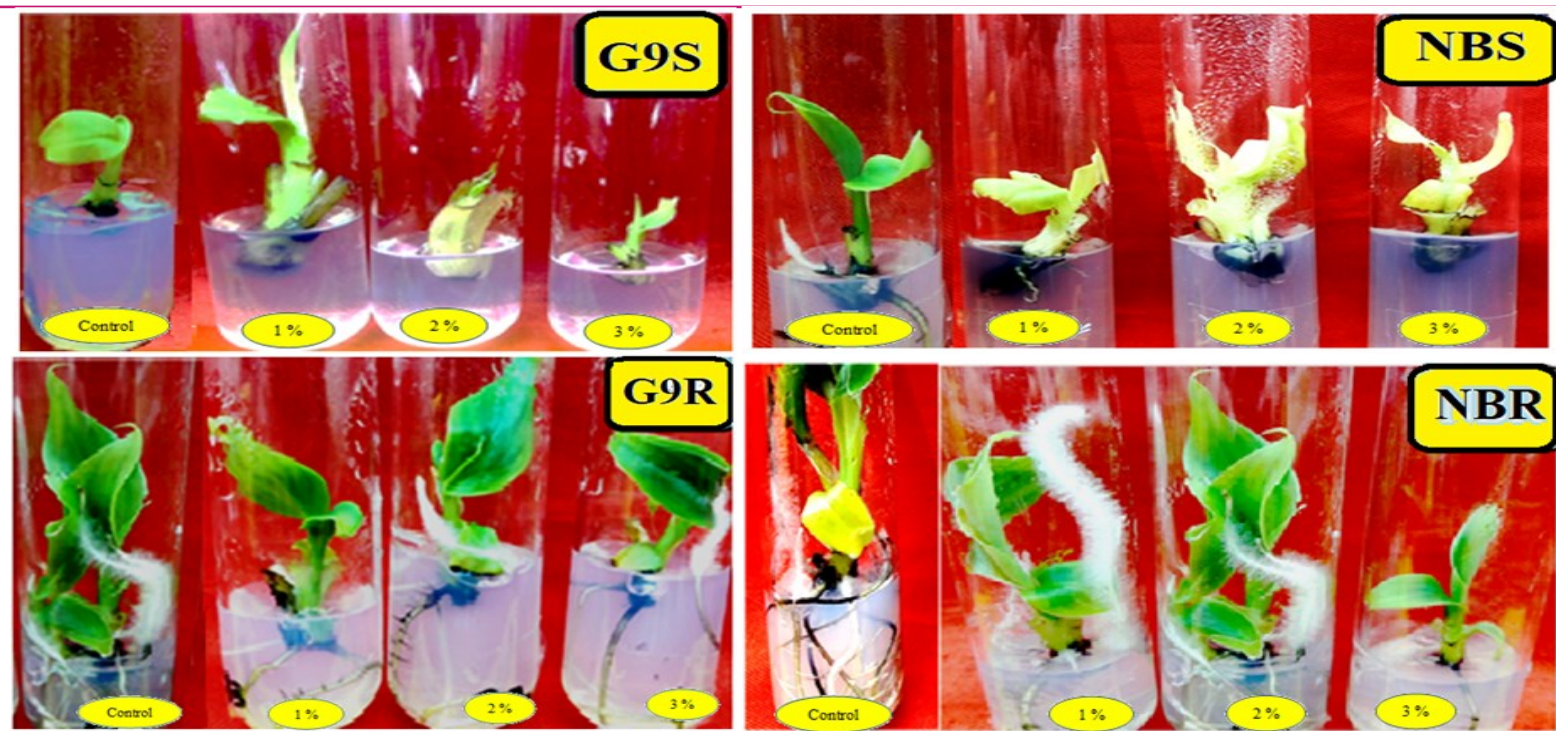

Fig. 1. Effect of various PEG concentrations on plant growth of banana genotype cv. G9- A\&B: shoot regeneration and rooting and Nalla Bontha- C\&D: shoot regeneration and rooting).

tol medium. Likewise, the highest root length $(8.5 \pm$ 0.25 ) was observed in $0.0 \mathrm{mM}$ and the lowest root length $7.0 \pm 0.14$ was recorded in $0.06 \mathrm{mM}$ Sorbitol.

Abiotic stress including drought, influence the growth rate and production of banana. Global agriculture production and availability of food is threatened by severity of drought (Bray, 2002; Lafitte et al., 2004; Magombeyi and Taigbenu, 2008). Therefore, the development of new tolerant banana varieties is highly required (Coachard Cochard et al., 2008). In the present study, osmotic stress was induced in shoot-tip explants of both the contrasting cultivars by using different concentrations of PEG and sorbitol. Both the osmotic inducers showed significant effects on shoot multiplication and root regeneration in banana cultivars. It was inferred that as the inducer concentration increased, morphogenetic responses of the cultivars tended to decrease. The controlled media i.e., MS media without any osmotic inducers (PEG and Sorbitol) produced the maximum number of shoots and highest shoot length followed by the maximum number of roots and root length. In contrast, MS media supplemented with PEG and sorbitol of different concentrations produced lesser number of shoots and roots.Similarly it was reported recently that all osmotic stress treatments restricted growth immediately in wheat genotypes, which was manifested as reduction of root as well as shoot lengths (Darko et al., 2019). Minimum no. of shoots and roots were produced on MS media supplemented with $3 \%$ of PEG and $0.06 \mathrm{mM}$ sorbitol, the same observation was also reported by Hajihashemi and Sofo, 2018 a reduction in plant overall growth in Stevia plants after treatment with $5 \%$ w/v PEG. Sorbitol cannot be considered as an energy source for banana plantlets, as its higher concentration declined the plant growth rate. Hence, sorbitol can be considered as an osmotic inducer that has a devastating effect on morphogenetic responses of plant Curcuma zedoaria Roscoe and Phaseolus vulgaris L. as reported by Mello et al. (2001) , in Solanum tuberosum by Gopal and Iwama (2007) and in Date palm by Al-Khateeb (2008). Negative effects of sorbitol on the growth of banana cultivars were due to its inability to mobilise plant cells (Mello et al., 2001). This inability can be related to its reduced uptake, insufficient sorbitol dehydrogenase in plant species (Jain et al., 1997 and Cuenca and Vietez, 2000). The root system is an efficient indicator of drought tolerance. A cultivar with a well-developed and strong root system is considered as drought tolerant (Kulkarni and Phalke, 2009). The findings of the present study indicated that Nalla Bontha maintained its root system under stress conditions to combat the deleterious effects on its growth. Whereas in Grand naine cultivar of banana minimum no. of roots and shortest root length was recorded in culture media with highest PEG and sorbitol concentration. Strong root system is thus considered as an adaptive response to water stress iduced via $P E G$ in rice (Oryza sativa L.) (Kato et al., 2006) same was observed in Arabidopsis thaliana where considerable loss was observed when comaparative study was done on mutents (Xiong et al., 2006 ) and Markesteijn and Poorter, 2009 demonstrated the same on tropical lowland dry deciduous forest studies for drought tolerance. PEG had a noxious effect on plant cells. High concentration of PEG was found to be more selective than the lower concentrations that ease discern between the contrasting cultivars in terms of drought tolerance. The present findings were found to be similar to the results of various researchers, Anber 2010 conducted the study using Mannitol \& PEG in Pelagonium; Rukundo et al., 2012 studied the effect of sorbitol in vitro banana plantlets; Lathyrus sativus (Barbara et al., 2014) while 
Eglal et al., 2015 studied effects of various PEG and trehalose on in vitro banana plantlets.

\section{Effect of osmotic stress inducer on physio- biochemical parameter of banana genotypes (cvs. Grand naine and Nalla Bontha)}

Different concentrations of Polyethylene glycol (PEG) were tested for some physio-biochemical parameter of banana genotypes. Proline content of the genotypes increases as the PEG concentration increases for both the genotypes, whereas the RWC value of both the genotypes decreases with the increase in PEG concentration from $0 \%$ to $3 \%(\mathrm{w} / \mathrm{v})$. The changes in the Proline content ( $\mu$ moles/g) and RWC (\%) of two banana genotypes (cvs. Grand naine and Nalla Bontha) maintained on MS medium containing various concentrations are shown in Table 3 .

It is evident from the data in Table 3 that there was no statistically significant difference in Proline content and Relative water content of Grand naine cultivar at various drought levels as compared to the control, however statistically significant differences were recorded in Proline and Relative water content of Nalla Bontha cultivar at various drought levels as compared to the control ( $0 \%$ PEG concentration). For both the cultivars, a gradual increase in the proline content was observed with a corresponding increase in drought level (PEG). In the control cultures the value of proline activity was $0.69 \mu$ moles $/ g$ for Grand naine and $1.99 \mu \mathrm{moles} / \mathrm{g}$ for Nalla Bontha cultivar. This value increased gradually and reac hed $1.00 \mu \mathrm{moles} / \mathrm{g}$ at $3 \%$ PEG concentration for Grand naine cultivar and $4.11 \mu \mathrm{moles} / \mathrm{g}$ at $3 \%$ PEG concentration for Nalla Bontha cultivar.

However, there was a gradual decline in RWC value with the increasing concentration of PEG from $0 \%$ to $3 \%(\mathrm{w} / \mathrm{v})$ for both the cultivars (Grand naine and Nalla Bontha). It was found that in controlled medium, the RWC value for Grand naine and Nalla Bontha cultivar was $73.06 \%$ and $81.77 \%$ respectively. This value gradually declined and reached $66.52 \%$ and $57.00 \%$ at $3 \%$ PEG concentration.

Different concentrations of Sorbitol were tested for some physio-biochemical parameter of banana genotypes. Proline content of the genotypes increases as the concentration of Sorbitol increases for both the genotypes, whereas the RWC of both the genotypes decreases with the increase in Sorbitol concentration from $0.0 \mathrm{mM}$ to $0.06 \mathrm{mM}$. The Proline content ( $\mu$ moles/ g) and RWC (\%) were directly proportional to changes in the sorbitol concentration. Water-stress situation diminish the plant metabolic pathways. Apparently, the quantity of metabolites is reduced so does the plant biomass (Kulkarni and Phalke, 2009).

It is evident from the data in Table 4 that there was no statistically significant difference was observed in Proline content and Relative water content of Grand naine cultivar at various drought levels as compared to the control. Whereas statistically significant differences was recorded in Proline and Relative water content of Nalla Bontha cultivar at various drought levels as compared to the control $(0.0 \mathrm{mM}$ Sorbitol concentration). For both the cultivars, a gradual increase in the proline content was observed with a corresponding increase in drought level (Sorbitol concentration). In the control cultures the value of proline activity was $0.72 \pm 0.14 \mu \mathrm{moles} / \mathrm{g}$ for Grand naine and $2.07 \pm 0.14 \mu \mathrm{moles} / \mathrm{g}$ for Nalla Bontha cultivar. This value increased gradually and reached 1.04 $\pm 0.20 \mu \mathrm{moles} / \mathrm{g}$ at $0.06 \mathrm{mM}$ Sorbitol concentration for Grand naine cultivar and $4.32 \pm 0.10 \mu \mathrm{moles} / \mathrm{g}$ at $0.06 \mathrm{mM}$ sorbitol concentration for Nalla Bontha cultivar.

However, there was a gradual decline in RWC value with the increasing concentration of Sorbitol from $0.0 \mathrm{mM}$ to $0.06 \mathrm{mM}$ for both the cultivars (Grand naine and Nalla Bontha). It can be inferred from Table 4 that in controlled medium, the RWC value for Grand naine and Nalla Bontha cultivar was $76.12 \%$ and $82.53 \%$ respectively. The value gradually declined and reached $59.12 \%$ and $69.37 \%$ at $0.06 \mathrm{mM}$ concentration of sorbitol.

Analyzing the genetics driving drought resistance in bananas is challenging, however, because of their growth requirements. To overcome this, Vanhove et al., 2012 analyzed in vitro banana plantlet growth rates in

Table 3. Effect of PEG on physio- biochemical parameters of banana genotype (cv. Grand naine \& Nalla bontha).

\begin{tabular}{llclc}
\hline & \multicolumn{2}{c}{ Grand Naine } & \multicolumn{2}{c}{ Nalla bontha } \\
\cline { 2 - 5 } PEG \% & $\begin{array}{l}\text { Proline content } \\
(\boldsymbol{\mu} \text { moles/g) }\end{array}$ & RWC (\%) & $\begin{array}{l}\text { Proline content } \\
(\boldsymbol{\mu m o l e s / g )}\end{array}$ & RWC (\%) \\
\hline 0 (Control) & $0.69 \pm 0.27$ & $73.06 \pm 3.04$ & $1.99 \pm 0.20^{\mathrm{c}}$ & $81.77 \pm 1.34^{\mathrm{a}}$ \\
1 & $0.74 \pm 0.14$ & $73.10 \pm 1.30$ & $2.47 \pm 0.50^{\mathrm{c}}$ & $78.52 \pm 8.79^{\mathrm{a}}$ \\
2 & $0.97 \pm 0.24$ & $67.12 \pm 5.29$ & $3.24 \pm 0.10^{\mathrm{b}}$ & $69.06^{\mathrm{b}} \pm 0.59^{\mathrm{b}}$ \\
3 & $1.00 \pm 0.21$ & $66.52 \pm 8.01$ & $4.11 \pm 0.10^{\mathrm{a}}$ & $57.00^{\mathrm{c}} \pm 0.20^{\mathrm{c}}$ \\
\hline
\end{tabular}

Data represents mean \pm SE of three replicates per treatment in three repeated experiments. Means within the same column followed by the different letters are significantly different according to DMRT at $5 \%$ level. 
Singh, A. et al. / J. Appl. \& Nat. Sci. 13(2), 482 - 490 (2021)

Table 4. Effect of Sorbitol on physio- biochemical parameters of banana genotype cv. Grand Naine \& Nalla Bontha.

\begin{tabular}{lllll}
\hline & \multicolumn{2}{c}{ Grand Naine } & \multicolumn{2}{c}{ Nalla bontha } \\
\cline { 2 - 5 } Sorbitol & Proline content & RWC (\%) & Proline content & RWC (\%) \\
\hline $0.0 \mathrm{mM}$ & $0.72 \pm 0.14^{\mathrm{b}}$ & $76.12 \pm 0.29^{\mathrm{a}}$ & $2.07 \pm 0.14^{\mathrm{d}}$ & $82.53 \pm 0.85^{\mathrm{a}}$ \\
(Control) & $0.72 \pm 0.14^{\mathrm{b}}$ & $70.30 \pm 1.07^{\mathrm{b}}$ & $2.54 \pm 0.22^{\mathrm{c}}$ & $79.43 \pm 1.26^{\mathrm{b}}$ \\
$0.02 \mathrm{mM}$ & $1.01 \pm 0.11^{\mathrm{a}}$ & $69.12 \pm 0.79^{\mathrm{c}}$ & $3.33 \pm 0.12^{\mathrm{b}}$ & $72.11 \pm 0.35^{\mathrm{c}}$ \\
$0.04 \mathrm{mM}$ & $1.04 \pm 0.20^{\mathrm{a}}$ & $59.12 \pm 0.80^{\mathrm{c}}$ & $4.32 \pm 0.10^{\mathrm{a}}$ & $69.37 \pm 0.30^{\mathrm{d}}$ \\
$0.06 \mathrm{mM}$ & 0 &
\end{tabular}

Data represents mean \pm SE of three replicates per treatment in three repeated experiments. Means within the same column followed by the different letters are significantly different according to DMRT at $5 \%$ level.

response to mild drought stress. The results pointed toward variants known to be more tolerant of irregular water availability in field settings. Analysis of leaf proteomes showed differences between stressed and nonstressed plantlets, with most of the proteome variation attributable to a handful of proteins.

Thus, in the present study biochemical and physiological parameters were assessed as they play an important in plants under drought stress conditions. As evident every plant has capacity to metabolizes different carbohydrates and the way an explant cultures will respond to different treatments of carbohydrates depends upon its genotype (Cuenca and Vieitez, 2000). Therefore, there is a need to select the type of carbohydrate that suits particularly the target specie so that the solute may be absorbed and metabolized by plantlets (Karhu, 1997; de Paiva Neto and Otoni, 2003). Proline and relative water content (RWC) were studied in the present investigation to access drought stress conditions. Different concentrations of PEG and Sorbitol produced significant effects on various parameters in banana plantlet produced in vitro. 4-weeks old grown in vitro banana plantlets were tested for Proline and RWC content. Proline content tends to increase as the concentration of osmotic inducers increases, whereas RWC shows an opposite effect. Its value decreases as PEG and sorbitol concentration increases. Similar findings were reported earlier in Eucalyptus tereticornis, where increase in D-mannitol concentration caused significant decrease in Relative water content (RWC) while higher levels of proline and sugar accumulation were recorded on medium containing $1000 \mathrm{mM} \mathrm{D-}$ mannitol (Singh et al., 2020) Proline accumulation was higher in culture media supplemented with higher concentration of Sorbitol and PEG in cv. Nalla Bontha, whereas cv. Grand naine showed lower accumulation. RWC declined considerably in cv. Grand naine, the results obtained was in accordance to the studies suggesting that sorbitol concentrations over $36.4 \mathrm{~g} \mathrm{~L}-1$ caused increase osmotic stress in the experimental medium, critically affecting the capacity of the plants to absorb water (Placide et al., 2012, Vanhove et al., 2012), whereas cv. Nalla Bontha was able to retain its water capacity even with high concentration of osmotic inducer. An ideal tolerant variety is such that shows reduced growth under drought stress implies to be drought resistant or tolerant. It re-confirmed by our results where Nalla Bontha, a presumed drought tolerant banana variety, showed the least growth reduction as compared to drought sensitive genotype Grand Nain, which showed more reduced growth.

It is difficult to study drought-tolerant varieties under environmental conditions because drought is difficult to control under field conditions, wherepphenotypic variations can occur, and there is no way to predict these environmental variations. Thus, for this reason tPEG and sorbitol as osmotic stress inducer were used at different concentrations on shoot-tip explants of banana genotypes with contrasting nature for drought tolerance. Both osmotic inducers showed significant effects on shoot multiplication and root regeneration in banana cultivars. Thus in vitro growth experiment will be a precise tool to screen the Musa biodiversity in Indian varieties for water stress tolerance. The contrasting varieties will be further explored and authenticated under induced environmental conditions to unveil the water scarcity stress phenomena in Musa germplasm.

\section{Conclusion}

Stress characterization has always been a pivotal step in understanding stress, thus a drought model experimental startup will be useful in conferring the multilevel functioning of plant physiology. In the current study, we tried to illustrate drought tolerance phenomena by determining growth parameters to simulate water stress in vitro to select drought tolerant banana genotypes. Banana plants were observed to be more susceptible to early drought stress as compared their later stages of growth. The physio-biochemical changes studied as knowledge in this field is still in infancy. It can be concluded that genotypes cv. Grand naine and cv. Nalla Bontha differed broadly in their response to drought stress and plants hold different adaptation traits to manage water deficit conditions under in vitro condition. Based on morphogenetic responses (shoot regenera- 
tion and rooting), physiological (Relative water content) and biochemical responses (Proline content), the genotypes Nalla Bontha were found to be more efficient than Grand naine genotypes. Thus, it can be concluded that Nalla bontha is drought tolerant in comparison to Grand naine, a drought sensitive genotype. This is the first step towards highlighting the trends of methodological developments in drought stress research in Indian Banana varieties. This study trends in physio-biochemical advances in drought stress evaluation in banana germplasm, thus paving the way for organizing traditional experimentation with phytohormone and reactive oxygen species (ROS) quantification, antioxidant enzyme activity assessment, and detailed transcriptome, proteome and metabolome profiling that are the need of the hour to quantify the Drought studies in Musa germplasm.

\section{Conflict of interest}

The authors declare that they have no conflict of interest.

\section{REFERENCES}

1. Al-Khateeb, A. (2008). Regulation of in vitro bud formation of date palm (Phoenixdactylifera L.) cv. Khanezi by different carbon sources. Bioresource Techno., 99,6550-6555. https://doi.org/10.1016/j.biortech.2007.11.070

2. Anber, M.A.H. (2010). Establishment of efficient in vitro method for drought tolerance evaluation in Pelargonium. Journal of Horticultural Science \& Ornamental Plants, 2 (1), 8-15.

3. Anjum, S.A., Xie, X., Wang, L., Saleem, M.F., Man, C. \& Lei, W. (2015). Morphological, physiological and biochemical responses of plants to drought stress. Acta Physiol. Plant., 37. https://doi.org/10.5897/AJAR10.027

4. Barbara, P., Kaminskai, I. \& Rybinski, W. (2014). Influence of PEG generated osmotic stress on shoot regeneration and some biochemical parameters in Lathyrus culture. Czech J. Genet. Plant Breed., 50 (2), 77-83. https:// doi.org/10.17221/110/2013-CJGPB

5. Basu, S., Ramegowda, V., Kumar, A. \&Pereira, A. (2016). Plant adaptation to drought stress. F1000Research, 23,5. https://doi.org/10.12688/f1000research.7678.1

6. Bisht, A., Singh, R., Gangwar, A., Singh, O. P. (2015). Export of Fruits from India: Growth, Pattern and SPS Issues. Economic Affairs, 60(2):339.

7. Barrs, H. D., \& Weatherley, P. E. (1962). A re-examination of the relative turgidity technique for estimating water deficits in leaves. Australian journal of biological sciences, 15 (3), 413-428. http://dx.doi.org/10.1071/BI9620413

8. Bates, L.S., Waldren, R.P. \& Teare, J. D. (1973). Rapid determination of free proline for water use studies. Plant and Soil., 39, 205-208. https://doi.org/10.1007/ BF00018060

9. Bikram, P. \& Bandita, D. (2019). Detection of phytochemicals and in vitro propagation of Banana (Musa variety Gaja Bantal). Journal of Medicinal Plants Studies, 7(1), 46 -49 .
10. Bray, E.A. (2002). Classification of genes differentially expressed during water deficit stress in Arabidopsis thaliana: an analysis using Microarray and differential expression data. Annals of Botany. 89, 803-811. https:// doi.org/10.1093/aob/mcf104

11. Cochard, H., Barigah, S., Kleinhentz, M. \& Eshel, A. (2008). Is xylem cavitation resistance a relevant criterion for screening drought resistance among Prunus species. J. Plant Physiol.,165, 976-982. DOI: 10.1016/ j.jplph.2007.07.020

12. Cuenca, B., \& Vieitez, A. (2000). Influence of carbon source on shoot multiplication and adventitious bud regeneration in in vitro beech cultures. Plant Growth Regul., 32:1-12. https://doi.org/10.1023/A:1006329510280

13. Darko, E., Végh, B., Khalil, R., Marček, T., Szalai, G., Pál, M., \& Janda, T. (2019). Metabolic responses of wheat seedlings to osmotic stress induced by various osmolytes under iso-osmotic conditions. Plos one, 14(12): e0226151. https://doi.org/10.1371/journal.pone.0226151

14. de Paiva Neto V.B., \& Otoni, W.C. (2003). Carbon sources and their osmotic potential in plant tissue culture: Does it matter? Sci. Hortic., 97:193- 202 https:// doi.org/10.1016/S0304-4238(02)00231-5

15. Eglal, M.S., Rania, M.A., Rana, A.A., Astin, G.S. (2015). Drought stress tolerance and enhancement of banana plantlets in vitro. Journal of Biotechnology and Bioengineering, 2(2),1-7.

16. Food and Agricultural Organization (2019). FAOSTAT Food and Agricultural Organization (FAO). Retrieved from: http:// http://www.fao.org/faostat/en/?\#data/QC. Accessed on Sat May 04 14:9:42 EAT 2019

17. Farooq, M., Wahid, A., Kobayashi, N., Fujita, D., Basra, S.M.A. (2009). Plant drought stress: Effects, mechanisms and management. Agron. Sustain. Dev., 29:185-212. https://doi.org/10.1051/agro:2008021

18. Gopal, J., \& Iwama, K. (2007). In vitro screening of potato against water stress mediated through sorbitol and polyethylene glycol. Plant cell rep., 26,693-700. https:// doi.org/10.1007/s00299-006-0275-6

19. Hajihashemi, S., \& Sofo, A. (2018). The effect of polyethylene glycol-induced drought stress on photosynthesis, carbohydrates and cell membrane in Stevia rebaudiana grown in greenhouse. Acta Physiologiae Plantarum, 40 (8):1-9. https://doi.org/10.1007/s11738-018-2722-8.

20. Jaleel, C.A., Manivannan, P., Wahid, A., Farooq, M., AlJuburi, J., Somasundaram, R., Panneerselvam, R. (2009). Drought Stress in Plants: A Review on Morphological Characteristics and Pigments Composition. Int. J. Agric. Biol., 11:7. https://doi.org/08-305/IGC-DYT/2009/11-1100-105

21. Karhu, S.T. (1997). Sugar use in relation to shoot induction by sorbitol and cytokinin in apple. Am. Soc. Hortic. Sci.,122, 476-480. https://doi.org/10.21273/JASHS.12 2.4 .476

22. Kato, Y., Abe, J., Kamoshita, A., Yamagishi, J. (2006). Genotypic variation in root growth angle in rice (Oryza sativa L.) and its association with deep root development in upland fields with different water regimes. Plant Soil., 287,117-129. http://dx.doi.org/10.1007/s11104-006-90084

23. Khan, S., Anwar, S., Yu, S., Sun, M., Yang, Z., \& Gao, Z. Q. (2019). Development of drought-tolerant transgenic 
Singh, A. et al. / J. Appl. \& Nat. Sci. 13(2), 482 - 490 (2021)

wheat: achievements and limitations. International journal of molecular sciences, 20(13),33-50.

24. Kulkarni, M., \& Phalke, S. (2009). Evaluating variability of root size system and its constitutive traits in hot pepper (Capsicum annum L.) under water stress. Sci. Hortic., 120, 159-166. https://doi.org/10.1016/j.scienta.200 8.10.007

25. Lafitte, H., Price, A., Courtois, B. (2004). Yield response to water deficit in an upland rice mapping population: Associations among traits and genetic markers. Theor. Appl. Genet., 109,1237-1246. https://doi.org/10.1007/s00122004-1731-8

26. Matheka J.M., E. Magiri, A.O. Rasha and J. Machuka, (2008). In vitro Selection and Characterization of Drought Tolerant Somaclones of Tropical Maize (Zea mays L.). Biotechnology, 7, 641-650. 10.3923/biotech.20 08.641 .650

27. Markesteijn, L., and Poorter, L. (2009). Seedling root morphology and biomass allocation of 62 tropical tree species in relation to drought and shade tolerance. J. Ecol., 97, 311-325.https://doi.org/10.1111/j.1365-2745.2008.0146 6.x

28. Mello, M., Dias, C.T.S., Amaral, A.F.C., Melo, M. (2001). Growth of Bauhiniaforficata Link, Curcuma zedoaria Roscoe and Phaseolus vulgaris $\mathrm{L}$. cell suspension cultures with carbon sources. Sci. Agric., 58:481-485. https://doi.org/10.1590/S0103-90162001000300007

29. Mohamed, M.A.H., Harris, P.J.C., Henderson, J. (2000). In vitro selection and characterization of a drought tolerant clone of Tagetes minuta. Plant Sci.,159: 213-222. http:// dx.doi.org/10.1016/S0168-9452(00)00339-3

30. Placide, R., Christian, C.S., Rony, R. (2012). Development of in vitro technique to screen for drought tolerant banana varieties by sorbitol induced osmotic stress. African Journal of Plant Science, 6, 416-425. https:// doi.org/10.5897/AJPS12.101

31. Ober, E.S. \& Sharp, R.E. (2003) Electrophysiological Responses of Maize Roots to Low Water Potentials: Relationship to Growth and ABA Accumulation. Journal of Experimental Botany, 54,813-824. https://doi.org/10.1093/ jxb/erg060

32. Ravi, I., Uma, S., Vaganan, M.M., Mustaffa, M.M. (2013). Phenotyping bananas for drought resistance. Frontiers in Physiology, 1, 82-123. https://doi.org/10.3389/fphys.201 3.00009

33. Rukundo, P., Carpentier, S.C., Swennen, R. (2012). Development of in vitro technique to screen for drought tolerant banana varieties by sorbitol induced osmotic stress. African Journal of Plant Science. 6(15), 416-425. https://doi.org/10.5897/AJPS12.101
34. Singh, D., Kaur, S. \& Kumar, A. (2020). In vitro drought tolerance in selected elite clones of Eucalyptus tereticornis Sm., Acta Physiol Plant 42,17. https://doi.org/10.1007/ s11738-019-3009-4.

35. Shao, H.B., Chu, L.Y., Jaleel, C.A., Manivannan, P., Panneerselvam, R., Shao, M.A. (2009). Understanding water deficit stress-induced changes in the basic metabolism of higher plants-Biotechnologically and sustainably improving agriculture and the eco-environment in arid regions of the globe. Crit. Rev. Biotechnol., 29:31-151. doi: https:// doi.org/10.1080/07388550902869792

36. Sharma, A., Kumar, V., Shahzad, B., Ramakrishnan, M., Sidhu, G. P. S., Bali, A. S., \& Zheng, B. (2019). Photosynthetic response of plants under different abiotic stresses: a review. Journal of Plant Growth Regulation, 1-23. https:// doi.org/10.1007/s00344-019-10018-x

37. Trenberth, K.E., Dai, A., Van der Schrier, G., Jones, P.D., Barichivich, J., Briffa, K.R., Sheffield, J. (2014). Global warming and changes in drought. Nat. Clim. Chang., 4, 17 -22. https://doi.org/10.1038/nclimate2067

38. Vanhove, A.C., Vermaelen W., Panis B., Swennen, R., Carpentier, S.C. (2012). Screening the banana biodiversity for drought tolerance: can an in vitro growth model and proteomics be used as a tool to discover tolerant varieties and understand homeostasis. Front. Plant Sci., 3, 176. https://doi.org/10.3389/fpls.2012.00176

39. Wilhite, A.S., \& Donald A. (1993). Drought assessment, management, and planning: theory and case studies. Springer Publication, Boston. ISBN 978-1-4613-6416-0.

40. Xiong, L, Wang, R.G., Mao, G., Koczan, J.M. (2006). Identification of drought tolerance determinants by genetic analysis of root response to drought stress and abscisic acid. Plant Physiol., 142, 10651074. doi: https://doi.org/10.1104/pp.10 6.0 84632.

41. Yadav, P.V., Suprasanna, P., Gopalrao, K.U., Anant, B.V. (2006). Molecular profiling using RAPD technique of salt and drought tolerant regenerants of sugarcane. Sugar Technol., 8, 63-68. https://doi.org/10.1007/BF02943744

42. Zhang, Q. (2007). Strategies for developing Green Super Rice. Proc. Natl. Acad. Sci. USA, 104:16402-16409. https://doi.org/10.1073/pnas.0708013104

43. Zhang, X., Lu, G., Long, W., Zou, X., Li, F., Nishio, T. (2014). Recent progress in drought and salt tolerance studies in Brassica crops. Breed. Sci., 64,60-73. DOI https://doi.org/10.1270/jsbbs.64.60

44. Zhao, T., \& Dai, A. (2015). The magnitude and causes of global drought changes in the twenty-first century under a low-moderate emissions scenario. Journal of climate, 28 (11),4490-4512.doi: https://doi.org/10.1175/JCLI-D-14-003 63.1 